\title{
Multiculturalism and legal autonomy for cultural minorities
}

\author{
Morten Ebbe Juul Nielsen
}

Philosophy, Department of Media, Cognition and Communication/Department of Food and Resource Economics, Copenhagen University

mejn@hum.ku.dk

Does multiculturalism imply that certain cultural minorities - nomos groups, whose cultural conceptions extend in important ways into views about the law - should have forms of legal autonomy that go beyond normal multicultural accommodations such as exemptions and special protection? In other words: should we allow «minority jurisdictions» for multicultural reasons and give certain minorities powers of legislation and adjudication on certain issues? The paper sketches how one might arrive at such a conclusion given some standard multicultural reasoning, and then proceeds by examining eight key rejoinders to such a proposal. None of these rejoinders provide by themselves knockdown arguments against extending multicultural rights to forms of legal autonomy, but together they do provide a basis for some skepticism about the cogency and desirability of at least more ambitious forms of legal autonomy for cultural minorities within a liberal framework.

Keywords: multiculturalism, law, minorities, liberalism, legal pluralism

\section{Introduction}

According to what might be called a common sense or «popular» view of the relation between a citizen and political authority, a citizen is subject, ultimately, to one law and one political authority, both normally to be identified with the nation state (and its institutions, including national law) in which the citizen lives. Reflection, of course, shows this to be an illusion, at least at the edges of the idea: we live in globalized times with many layers and forms of relevant law and regulation (national, international, global.) Nevertheless, this monist picture - one citizen, one law, one ultimate political authority is, I surmise, firmly held as a kind of mental default picture by most citizens and many scholars as well. In this article, I want to pursue some normative questions that could arise if we deliberately and openly deviated from the monist picture by allowing multiple and overlapping jurisdictions for reasons of culture. The idea - to be unfolded later - connects with some strong currents in contemporary multiculturalism: In order to properly recognize, or respect, or accommodate cultural minorities, multiculturalists argue, it is sometimes necessary to grant such minorities certain exemptions, or privileges, or special rights. However, it might be argued that one way of recognizing (or respecting) cultural 
minorities is bestowing upon them certain legal powers (to adjudicate, legislate, etc.) for their own members. This I call multicultural multilegalism. So, we arrive at the guiding question of this article: Which normative concerns could arise in conjunction with such multicultural multilegalism? To grapple with those normative issues, one needs first to define and discuss the concept, which is done after some initial comments on the present state of the art in the multicultural literature and other preliminaries (in this introduction). Between these two main parts of the article, why one might opt for such multicultural multilegal arrangements in the first place is briefly discussed.

Multiculturalism ${ }^{1}$ has been widely discussed by scholars of many different disciplines and persuasions over the last couple of decades. ${ }^{2}$ An under-discussed issue here concerns the connections between multiculturalism and law, or legal philosophy. Of course, academics such as Will Kymlicka have written extensively about issues concerning multiculturalism, rights, and the state. Hence, thoughts concerning law are present in the multicultural literature in a trivial sense. What I have in mind is the literature concerning a more tangible connection between law and multiculturalism, specifically, forms of legal autonomy granted to «cultural minorities» qua cultural minorities, and even more specifically, (forms of) legal autonomy of cultural minorities within the framework of a majority state, the aforementioned «multicultural multilegalism.»

Canadian scholar Ayelet Shachar (2001) did grapple with some pertinent aspects of this issue. Central to Shachar's line of thought is the idea of a Nomos group: roughly, a group whose collective identity is at least partially, and in some crucial sense, dependent on or constituted by an outlook of how the law ought to be. ${ }^{3}$ Typically, this intertwines with deeply held cultural preferences. One example here is the view of some Moslems concerning family law. Shachar's work was seminal in discussing the idea of (forms of) «intra-state» legal autonomy for cultural minorities within a broadly liberal framework, and with an emphasis on multicultural theory. Although only a few of the normative problems that might arise from such arrangements are discussed, the work quite thoroughly addresses one very important issue, namely the issue of in-group marginalization of women. Another scholar, Jeremy Waldron, has been somewhat more systematic in discussing normative problems associated with intra-state legal autonomy for cultural minorities (Waldron 2002, 2007) and much of what follows in this article is a critical response to (and expansion of) his critique. Waldron's arguments are instructive; yet, his mainly negative appraisal of the prospects of multicultural multilegalism seems to be too hasty. Moreover, it misses or disregards some other relevant normative issues that deserve discussion.

The guiding question of this paper is, as mentioned, "the normative concerns that could arise in conjunction with multicultural multiculturalism». An assessment of these concerns is, of course, important to ascertain another issue, namely, «whether (some) cultural minorities should have (forms of) legal autonomy given multiculturalism.» However, my conclusion is rather modest: none of the normative concerns arising from multicultural multilegalism analyzed here are by themselves knockdown arguments that can settle the issue. Nevertheless, taken together, they do seem to provide reasons for 
skepticism about the cogency and, all things considered, the desirability of at least any more ambitious form of multicultural multilegalism.

\section{Multicultural multilegalism}

There is a long tradition for the study of legal pluralism ${ }^{4}$ (roughly, legal pluralism is a state of affairs in which more than one legal authority claims sovereignty or jurisdiction over the same person, or the same territory, or the same issue, and these authorities are not neatly ordered in a hierarchical system giving one authority precedence over another). ${ }^{5}$ Setting aside some definitional issues that are discussed in legal theory, I treat "Multilegalism» here as a species of legal pluralism. ${ }^{6}$ Minimally, it consists in the suspension of the majority jurisdiction's (the state's) comprehensiveness: its claim to have the right to decide on all issues, at least in principle. The majority jurisdiction hands over legal powers to, and thereby creates, a «minority jurisdiction» concerning some issues, for example, those relating to family law. In short, multilegalism (according to this minimal definition) obtains when the state confers certain forms of legal autonomy to some (minority) group, which then can be said to establish a minority jurisdiction (concerning at minimum one issue) «alongside» or rather inside the normal legal framework of the state.

Here, we can distinguish between three «arenas» of legal autonomy or powers: legislative, concerning the right to make laws (regulating at least one area of concern); adjucative, concerning the right to rule in courts; and status-conferring, concerning the issue of whether or not some issue or person belongs in this rather than that jurisdiction.

However, the interest of the present article is not multilegalism per se, at least, not in the minimal sense just described; after all, we are quite familiar with forms of multilegal arrangements, for example, of the kind where labour unions and employer organizations have certain rights to make binding agreements concerning wages. Rather, what I am interested in is the state of affairs when a group of people get certain forms of legal autonomy for reasons of their culture.

The aim of this article is not to analyze present states of affairs that might, or might not, be said to constitute multicultural multilegalism. One reason for this is that some of the examples that might pop up at first glance, such as certain religious councils, do not fall under the scope of multilegalism as defined above, insofar as they are not formally, that is, de jure, recognized by the state, even though they might be effectively, or de facto, recognized and working in practice. Of course, some of them are, such as the Jewish Beth Din court dealing with family law in England; ${ }^{7}$ however, the aim of this article is to draw attention to some generic normative issues that are more or less independent of the concrete and actual arrangements of specific extra- or quasilegal institutions. Rather than analyzing particular empirical examples, the idea is to ask certain questions: What kinds of moral reasons could give rise to the formal recognition to separate, though they may be interconnected, legal systems within the same system? And, first and foremost, what normative challenges could arise in conjunction with multicultural multilegalism? 
Although the article does not analyze present empirically given examples, it addresses a very real and live issue. Given the (rather obvious) present state of multiculturalism (sociological or empirical) in western countries, various parties sometimes voice the opinion that minorities (cultural, ethnic, religious) ought to have certain forms of legal autonomy, which would, in effect, amount to multilegalism. ${ }^{8}$ Hence, apart from a narrow legal or jurisprudential discussion of multilegalism or, more broadly, legal pluralism, a wider legal, philosophical, and normative analysis is called for.

In sum, multicultural multilegalism in the sense used here involves de jure acknowledgment of plural and potentially overlapping or competing jurisdictions: in casu, of a «minority jurisdiction» within a «majority jurisdiction» ${ }^{9}$ and the reason for the acknowledgment of such a minority jurisdiction is essentially connected to some perceived cultural aspect(s) of the minority.

\section{Why multilegalism?}

We now have a basic concept of multicultural multilegalism. Before proceeding to the discussion of the moral challenges such arrangements could entail, it is timely to briefly consider why one might suggest such a division of legal status within a majority jurisdiction. The aim of this section is not to argue that we ought, all things considered, to accommodate cultural differences by way of multicultural multilegalism. Rather, it is to sketch some arguments that, if properly expanded, might constitute reasons that point in that direction.

In the contemporary philosophical debate over multiculturalism, one can extrapolate three general ways of arguing that could lead to the conclusion that we ought to give cultural minorities special legal recognition in the sense that we ought to acknowledge at least a part of their own conceptions of law or rules for at least some part of their own affairs. ${ }^{10}$ Multiculturalists in the advocatory sense agree that difference-blind rights are not always sufficient to achieve a fair treatment of minorities. Liberal multiculturalists argue generally that some minorities are worse off through no fault of their own, because access to cultural goods is more expensive when one belongs to a minority and because they bear the higher transaction costs of living in culturally foreign settings. The main argument of the most influential liberal multiculturalist, Will Kymlicka et al. ${ }^{11}$ is a bit more complex: he argues ${ }^{12}$ that access to one's own «societal culture» is a constituent part of the ability to form and revise a conception of the good. Hence, social justice needs to be concerned with culture because the good of access to one's own culture might be distributed unequally. In any event, liberal multiculturalists argue on egalitarian terms. (Kymlicka 2002: 135ff; 1989; Cf:Festenstein 2005: 70ff). Second, another multiculturalist tradition is established by, or takes its cue from, neo-Aristotelian philosophers such as Charles Taylor or Alex Honneth and argues that we must recognize minorities and their claims because recognition is a basic normative notion of great importance. In short, they argue in terms of recognition (Taylor 1994; Honneth 1995). Third, a diverse cluster of theories argue that we owe each other respect, which in turn means respect for a person's 
or a group's identity. The central notion here is respect for identity, or rather, for difference $^{13}$ (e.g., Modood 2007; Parekh 2006; Young 1990).

It cannot be ignored that views concerning law, just punishment etc. are, or at least can be, important components of people's identities, and to suppose that these views are somehow more «external» or less «culturally determined» than, for example., views on religion or sexual mores, is simply wrong. If we must give political priority to «recognition of cultural differences» or "respect for identity», then, ceteris paribus, we must sometimes extend this respect to take the form of legal arrangements of a multilegal kind. This is, of course, not to say that all claims of identity or culture should lead toward multilegalism. It is only, or at least mainly, relevant for «nomoi groups» such as discussed in Shachar (2001). ${ }^{14}$ Although it is probably true that the concept of a nomos group is somewhat undertheorized, its rough outline should be familiar enough: A nomos group is a sufficiently identifiable and stable group of persons who share an allegiance to some system of rules or belief in some norm(s) of law that go beyond what can plausibly be accommodated within «normal» muliticulturalist visions of the state. They «share a comprehensive world view that extends to creating a law for the community» and have a «normative universe in which law and cultural narrative are inseparably related.» ${ }^{15}$ It is true that many of the rules and ideas held by cultural minorities can easily be accommodated within a «monist» system of law, as the law itself is replete with exceptions and qualifications. For example, orthodox Jews (arguably a nomos group, or perhaps several nomoi groups) need not have legal autonomy in order to have reasonable access to kosher foods. All they need is an exemption from certain rules governing the slaughter of animals. However, the wish to be the source of (certain) rules and have the authority to adjudicate in certain cases cannot be adequately described as «exemptions.» Meeting such demands perhaps calls for forms of legal autonomy, or multilegalism. ${ }^{16}$

In a nutshell, then, the multicultural argument for multicultural multilegalism (vis-àvis genuine nomoi groups) could take three forms: We could give forms of legal autonomy to certain minorities because (a form of) legal autonomy is 1) required by equality (here, equality in the access to or control over what follows from «one's own conceptions of the law»), 2) an extension of the proper form of recognition (here, recognition of different conceptions of the law), or 3) a proper way of accommodating plural identities (here, identity as «belonging to this or that nomoi group.»)

\section{The normative concerns}

We now have both an idea about multicultural multilegalism and why one might think that such arrangements are justified. In the following sections, eight different possible problems or obstacles for multilegalism are presented and analyzed: In order: 1) the problem of «which law?»; ${ }^{17}$ 2) the worry that multilegalism will lead to an undue increase in social transaction costs; 3 ) the problems concerning the «cultural defence»; 4) the idea that multilegalism is self-defeating because salient cultural differences will reproduce themselves within minority jurisdictions; ${ }^{18}$ ) the idea that multilegalism is in itself unde- 
sirable, qua its incompatibility with universalistic solidarity and equality; 6) the worry that genuine multilegalism is incompatible with some people's due rights; 7) the problem of recognition; and finally, 8) the worry over undue cultural essentialism.

\section{Which law?}

In any multilegal arrangement, there is the possibility that the law of the minority jurisdiction will clash with that of the majority jurisdiction, and in more advanced cases, we can have clashes between two or more minority jurisdictions. The key question here is the following: Which (system of) law should take precedence? «Choice of law theory» is the branch of legal theory that concerns the «awkward fact» that we have distinct jurisdictions, specifically, the issue whether or when a foreign law is relevant to a case. ${ }^{19}$ So, the problem of «choice of law» is evidently not particular to multilegal arrangements. Choice of law theory aims at giving a rationale to explain what legal material from which jurisdictions are relevant in which cases, and to provide a theory of their internal ranking. However, there is no consensus on which rationale should prevail, and it seems evident that legal and political theorists need to face up to the extra complications of multilegalism. If we have a case involving parties from two different jurisdictions, we should first have to decide which court should decide on the question of choice of law (or simply, which law should take precedence.) Once this is established, the question arises whether that court should base its decisions on «vested rights», for example, pre-existing rights created in the jurisdictions in question, or whether it should think of itself as creating its own rights. The problem with the first alternative becomes clear if we imagine that the laws of the jurisdictions in question would lead to different and incompatible decisions. In the absence of some substantial reason to decide in favour of one over the other jurisdictional interpretation, what is this neutral court to do? On the other hand, having preestablished rules for deciding which court/law should take precedence threatens either to undermine the very point of multilegalism (if we, by default, take the view that the majority jurisdiction's laws or courts should take precedence) or to treat members of the majority jurisdiction unfairly, because it submits them to a system of law to which they have not given their consent. In any event, there is the risk that at least one of the parties to the conflict is not treated legally in accordance with the party's original jurisdiction.

So, it is obvious that any kind of multilegal arrangement must include second-order rules for «deciding how to decide» in cases involving parties from different jurisdictions in order to retain any claim to plausibility. It would exceed the limits of this paper to pursue the matter at a greater length, but to exemplify, maybe for criminal law cases (e.g., cases of violence or theft), the rules (and institutions) of the majority jurisdiction should take precedence, while family law matters should be the prerogative of the minority jurisdiction. If such rules are specified beforehand as part of the distinct legal arrangements themselves, the complaint that some party is not being treated in accordance with his or her original jurisdiction will disappear. And at least some of the more technical problems concerning how to decide in choice-of-law problems will be alleviated. Whether this is 
possible while maintaining «the spirit» of multicultural multilegalism and respecting the legal status of majority jurisdiction citizens, however, remains unclear.

Moreover, the choice-of-law type of problems also apply to questions concerning entry and exit from jurisdictions. Imagine a person performing something illegal in jurisdiction at time $t$, leaving (as in dropping membership of) that jurisdiction and entering another one at $\mathrm{t} 2$, and being «found out» at $\mathrm{t} 3$. Should the original $(\mathrm{t} 1)$ or the present $(\mathrm{t} 3)$ jurisdiction take precedence? Permutations of such problems are easy to imagine, and not all of them can find an easy normative solution (although court solutions might be less problematic from a purely legal point of view.) Nevertheless, and in sum, although second-order rules of decision in «which law?» types of problems do not dissolve all worries, they arguably do alleviate some of the greater problems, and since we already encounter many choice-of-law conundrums without this, it makes us question the desirability or legitimacy of current legal systems; the question of «which law?» is not decisive.

\section{Increased social transaction costs}

Any multilegal arrangement will increase the social transaction costs in society because it multiplies the legal possibilities (positive or negative) in inter-group transactions. Simply put, when dealing with members of the same legal system, one can be confident in one's own knowledge (implicit or explicit) about the legality of what one is undertaking. The situation is (potentially, at least) much more complicated when involving several jurisdictions in one's affairs with other persons. When dealing, on a mundane, daily basis, only with members of one's own jurisdiction, it is easy to know what rules apply. So, a shopkeeper need not concern himself with the eventual existence of different rules of commerce vis-à-vis different customers. As an increase in social transaction costs is ceteris paribus undesirable, this counts against multilegalism (cf.: Waldron 2007: 131 et circa.)

However, this should probably not worry proponents of multilegalism too much. After all, qua globalization, we already live in a vastly complicated network of different legal systems, and much of our everyday dealings concerns members of other legal communities. Probably, an atheist shopkeeper knows she is sailing very close to the wind if she purveys pork rinds to underage Moslem or Orthodox Jewish kids in the neighbourhood, even if she is not legally obliged not to do so under most current laws in the western world. It would be too cavalier an attitude to dismiss the worry altogether, though. Very complicated forms of multicultural multilegalism, with many repercussions for our daily interaction, are clearly imaginable. But in the end, it cannot be a decisive criticism of multilegalism; rather, it is one of the many factors to be weighed in an all-things-considered assessment of the desirability of a specific multilegal arrangement.

\section{The cultural defence}

Waldron (2002: 12f; 2007: 131ff. See also Phillips 2003: 513f) voices the concern that multilegal arrangements might provide a background for gross injustices via the so-called 
«cultural defence». In brief, the cultural defence is the invocation of «cultural beliefs» that (allegedly) justifies otherwise unjust or wrongful actions («in my culture, the woman is supposed to be obedient; if not, it is morally right to beat her up.») Barring trite relativistic manoeuvres, such defences are to be eschewed from the moral point of view. ${ }^{20}$ The potential conflict between basic moral rights and multilegalism is dealt with later; here, the question is only whether or not multilegalism necessarily engenders or accentuates such conflicts.

One reason why multilegalism could be taken to lead to such unpalatable consequences is that a cunning defendant could claim membership of a minority jurisdiction that would fit his or her case (by providing a cultural defence.) However, if one made membership of a legal community a post facto phenomenon, it would seem bizarre. Rather, membership of a minority jurisdiction should be 1) voluntary and 2) ex ante, for example, something that one should decide on reaching the age of consent. This would remove the worry that Waldron (2007) expresses.

Nevertheless, a more horrifying picture arises if one imagines powerful elites immunizing themselves from legal sanctions by simply building a (multilegal) law system giving legal and/or political privileges to, for example, men, religious leaders, and clan plutocrats. No morally defensible system should permit this. But the point to note at this juncture is that this need not be the case: there is, of course, no necessary connection between granting forms of legal powers to minorities and the creation of unjust legal systems. Against this, it might be claimed that, since problematic cases of the invocation of the cultural defence are already encountered in present legal systems (see Phillips 2003), the worry is that multicultural multilegalism will exacerbate and intensify the problems of the cultural defence. But again, this is not something that follows by necessity from the mere fact of granting forms of legal powers to minorities; it is a purely contingent question whether this will be the case. ${ }^{21}$

\section{Self-defeating multilegalism}

Waldron also raises the worry that multilegalism is in a sense "self-defeating», because «the situation of plurality and difference will quickly reproduce itself» (Waldron 2007: 143). The contention is that if we need to meet cultural plurality, that is, difference, with forms of multilegalism, then we will end up in a situation with myriads of small legal systems, because differences will keep reproducing themselves within ever smaller jurisdictions.

This is a difficult challenge to assess. On the one hand, Waldron is right to point out that differences, even salient ones, will reproduce themselves (barring totalitarian methods to suppress intra-group dissent) Hence, it is a logical possibility that all individuals have a claim to their own, special legal system - surely an absurd implication of multilegalism. However, there are reasons (empirical rather than conceptual) to believe that not all kinds of multilegalism will have this implication. First of all, it is not given that all persons would prefer entering into minority jurisdictions (again, it should be stressed that voluntary membership of a minority jurisdiction seems to be an obviously necessary con- 
dition for legitimacy.) Secondly, a justifiable form of multilegalism would need a solid underpinning, for example, that a given multilegal arrangement is justified for egalitarian reasons. And not all minority jurisdictions could be justified in that way. Third, as regards multicultural multilegalism, its underpinning would need to concern the existence of $a$ culture. Even if it is granted - reasonably so - that «culture» is a fluctuating, blurry concept, it seems fair to say that one in almost all relevant cases needs a rather large group of people to constitute «a culture». Intra-cultural disagreement over even quite important aspects of a culture, say, some dispute over a theological detail, does not necessarily merit talk of a cultural split, establishing two rather than one culture.

Nevertheless, forms of multilegalism justified by way of recognition of difference (and the like) could easily embroil themselves in absurd conclusions, for there are often no good reasons to surmise that we can easily, or even theoretically, distinguish between authentic and spurious claims about salient cultural difference (cf.: Johnson 2002). And it might be asked why we should only give those strong in numbers legal autonomy, given it is difference and respect for culture which drives the claim to legal autonomy? Hence, the worry about fragmentation into ever smaller «cultural» jurisdictions cannot be completely ignored.

\section{Incompatibility with solidarity and equality}

It might be averred that multilegalism undermines certain important senses of equality, and that this is closely connected to a regrettable loss of social solidarity in the community or state. Waldron is worried that «legal decentralization» is undesirable in itself, because we have «a general obligation to come to terms with those we happen to live near, and not to try to manipulate boundaries and populations so that we only live near those whom we like or those who are like ourselves» (Waldron 2007: 143). Waldron ground this line of thought in Kant's political theory, emphasizing that political communities should try to solve the problems of difference through universal laws, not by changing (the boundaries of) the political communities themselves. I believe it is dubious whether one can press the line of argument that «legal decentralization» or multilegalism is in itself undesirable, even given strong Kantian premises, for it seems to be the case that we in certain circumstances fulfill duties of equal respect and civility by allowing some individuals to form their own legal communities (this is, for instance, true for some cases of secession.)

Moreover, it is not altogether clear that multilegalism necessarily undermines equality in any relevant sense. Granted, multilegalism would mean introducing more differences (namely, differences in legal status for some issues for different citizens, where this difference did not exist beforehand), but much of law's work is to introduce differences (between, say, the guilty and the innocent, the debtor and the creditor, etc.) That being said, it is evident that some practices that could follow from multilegalism might constitute gross violations of relevant norms of equality, say, if a minority jurisdiction introduces salient differences in legal status between men and women, or castes. 
Some instances of multilegalism might very well be held to be undesirable in terms of the consequences they might have for social solidarity, and hence, for equality. For example, if or to the extent multilegalism contributes to undermining important senses of social cohesion, necessary for a comprehensive redistributive programme (for a discussion of this, see Banting \& Kymlicka 2006: 10-30), it would be undesirable in terms of distributive equality. Social cohesion could also be claimed to be desirable in itself, or at least as desirable notwithstanding its relevance for redistribution. At the end of the day, it is an empirical question whether or not multilegalism would undermine social cohesion. It is also unclear where the "trade-off point» between social cohesion and the forms of respect for differences encapsulated in the idea of multilegalism is. One might believe that multilegalism could be justified even if it means tempering redistributive ambitions across jurisdictions; conversely, one might hold resource redistribution to be of prime importance, outweighing any claims that could undermine redistributive objectives (for a discussion of some of these issues, see Fraser \& Honneth 2003). This controversial issue is beyond the scope of this paper.

In any event, the question whether or to which degree multilegalism might contribute to undermine social cohesion is not a matter to be taken lightly in assessing the cogency and desirability of multilegalism. This makes the worry over social cohesion a particularly difficult one to address in abstract philosophical terms. Different minorities will have different claims about which forms (and which scope) of legal autonomy are mandated or necessary to meet multicultural goals; they will do so in different social settings (e.g., one in which the minority in question is generally welcomed vs. one where it is met with skepticism) and indeed, the same goes for variations in economic and political environments. Clearly, the force and plausibility of the worry over social cohesion is very much dependent on both the forms and the scope of the demands for legal powers and the general societal setting in which they take place. This also means that, even if it can be argued that it would be a morally good thing to instigate some form of multilegalism, when social settings are abstracted away, the very same social settings might undermine the desirability of doing so. This again invites a piecemeal approach, and one which is highly sensitive to context.

\section{Is multilegalism in conflict with persons' rights?}

In liberal societies, the state is given a monopoly of coercion, among other things because the liberal state is seen as the best way of ensuring basic civil and political rights.

Multicultural multilegalist rights can clash with such basic rights. Suppose that we have a right to free conscience protecting us against the worst social consequences in cases of apostasy. Suppose, furthermore, that we have a right to cultural recognition that extends into certain multilegal rights of legal autonomy in deciding how to interpret freedom of conscience. What, then, if a cultural dissenter belonging to a minority jurisdiction commits «the crime of apostasy»? Should we say of such a person that his or her cultural identity takes precedence - that the person's cultural right to multilegal arrangements is the most important one? Even in spite of the person's actions? Or should we say 
that the person's basic right to freedom of conscience is more fundamental and more important?

All possible answers to such and similar conflicts involve problems: To insist that multicultural multilegal rights take precedence can involve the following contradiction: By violating the cultural standards, the active party is necessarily not accepting those standards (with the exception of cases of practical irrationality.) It flies in the face of common sense to insist that it is «more respectful» to treat persons in accordance with their cultural tradition than it is to treat them in accordance with their revealed preferences, at least insofar as basic rights have not been violated. Hence, the question remains: How far should we go toward accommodating culturally based normative propositions and treat them as legally justified? Do we draw the line at special rules for the slaughtering of animals? Or at legal repercussions for apostasy? Taking the «difference-blind» way out and insisting that basic rights always take precedence removes such worries, but engenders another one, namely, why should we have multilegal rights in the first place? We do have a system of handling private disputes, that is, private law; we have democratic rights of association, freedom of conscience etc. giving at least a quite broad range of possibilities for people to arrange the social world in accordance with their preferences; and democracy ensures people's proportional right to be heard. Where, then, is the need for multilegal rights (beyond some extremely circumstantial instrumental purpose?) Trying to avoid both horns of the dilemma, one might insist that there is no principled answer to the question about the relative weight of cultural vs. basic rights. This will leave both the first-order minority jurisdiction rules and the second-order decision rules without justification beyond public expediency, something hard core legal relativists and moral skeptics might embrace, but few others would.

Naturally, it need not be the case that a minority must compromise basic human rights or the moral boundaries of what, for example, a liberal or decent people (using Rawls' (1999) terms from The Law of Peoples) can or should tolerate. In general, it could be surmised that any justifiable multicultural multilegal arrangement should abide with Kymlicka's idea that cultural minorities can claim a right to «external protections» but not to instigate «internal restrictions» (see, e.g., Kymlicka 1995: 35ff) - again, the issue of the voluntariness of the multilegal arrangement pops up as a decisive moment: internal restrictions that impede the autonomy of minority jurisdiction members are morally problematic, and genuinely voluntary membership is necessary (but not sufficient) for legitimacy. ${ }^{22}$ Moreover, rights are subject to interpretation within a reasonable scope, and both circumstances and moral theory might point in the direction of the plausibility and desirability of certain multilegal arrangements, where minorities are allowed to partake in the interpretation of rights within a (probably) rather confined legal space. Waldron's example of the non-sexual character of an Afghani father kissing the penis of his baby son (Waldron 2002: 5ff; 2007: 150f, referring to State vs Kargar) is illustrative: without the "culturally informed» interpretation - the knowledge that in this cultural group, fathers kissing the penis of their baby sons is definitely not a sexual act - the majority jurisdiction could not reach a fair verdict (given the premise is true, of course.) But, and this is the important point, there is no establishment of any kind of autonomous legal institution or 
granting of legal powers involved here. It could all take place within a monist legal system that is adequately geared toward sensitivity of culturally determined differences.

\section{What about recognition?}

As mentioned in the above section, one of the avenues that could make multilegalism plausible involves recognition. This is a surprisingly complex notion (see, e.g., the discussion in Ikäheimo 2002); nevertheless, the key argument is, at least superficially, straightforward. If or to the extent that «recognition» is a central component in the formation of a stable self necessary for a decent human life, and insofar as we owe such recognition to each other as persons and as citizens, then, ceteris paribus, we need to respect or acknowledge the cultural identities of persons. Now, normally «cultural identity» is taken to include such rather mundane stuff as ethnically or religiously defined holidays, modes of consuming and producing food, and traditional or religious clothing as well as more politically controversial phenomena such as language policies or school curricula, but not any legal conceptions that might be culturally (co-)defined. But it seems evident that legal conceptions (e.g., concerning justice, punishment, tort, family law, etc.) can be as important to persons and their identities as any of the other issues normally associated with cultural identity. Again, Shachar's conception of a nomos group springs to mind, a shared legal identity expressing specific legal conceptions and norms.

If this is true, then it seems at least theoretically cogent to say that if or insofar as social justice sometimes demands special recognition of special cultural identities, this can be expanded into recognition of «legal identities», that is, specific legal ideas that cannot be accommodated within the majority system. And then, there is a starting point for an argument in favor of multilegal arrangements: After all, how can it be that persons' conceptions concerning religion, morality, mores and customs can be sufficiently strong or important to ground an exception from the majority in terms of special group rights, but not the same persons' conceptions concerning the law?

As mentioned, the concept of recognition is extremely complex, and one cannot do full justice here to the line of thought described. However, there are two reasons for being skeptical, not concerning recognition per se but the conclusion that recognition mandates multilegalism, that merit attention:

First, if one takes the cue from Honneth's theory of recognition, there is a rather glaring conflict in the suggestion that we should accommodate persons' subjective legal conceptions by way of establishing separate, quasi-autonomous legal systems. For Honneth, we recognize citizens when it comes to legal recognition (the «second sphere of recognition»), and citizens are defined, not in subjectivist or particularist terms, but in quite the opposite: as equal (and, in certain respects, sufficiently alike) legal subjects. Hence, insisting on pigeon-holing persons into cultural legal identities could easily become a form of misrecognition. In effect, it is to claim that "you are too different, too alien, to be a member of our legal community.»

Second, one could eschew Honneth's framework and go for some other theory of recognition, for instance, Taylor's. It is quite difficult to pin down the exact practical 
implications of Taylor's thesis of recognition, but it is noteworthy that he does not himself seem overly inclined to include forms of legal autonomy in the package. The standard picture is as follows: Yes, certain culturally (ethnically, linguistically...) defined groups deserve certain special rights, for example, language rights, but these rights are embedded within a largely unified legal framework. Why is that? One plausible reason is that on the one hand, a sufficiently liberal society gives leeway to individual (and collective) legal conceptions within civil law - if two parties can come to an agreement in a civil law court, and that agreement is not a violation of other legal rights and duties, then the parties can justify their agreement with more or less whatever they want to, including their own (and presumably shared) legal conceptions. But on the other, a liberal society wants to protect individuals against undue social (and legal) coercion, that is, certain legal and political rights take precedence, and it is among the prime tasks of a liberal state to ensure that these rights are not violated. Hence, various special «cultural rights» might be given to individuals or groups, but the best way to protect individuals is to maintain one legal framework wherein these special rights are embedded. Civil law and special rights, it could be argued, suffice for recognition if we want to protect individuals as well.

\section{Undue cultural essentialism}

According to some critics, multiculturalism is in a certain sense chimerical because it relies on an unfounded essentialist notion of «culture». Culture, so the argument goes, is a fluid, negotiable, and rather politicized concept, and to assume that persons «belong» seamlessly to a single «culture» is both descriptively false and normatively dangerous. But the very concept of multicultural multilegalism relies on the idea that there are two or more sufficiently distinct cultures into which we can pigeonhole persons. Hence, it relies on an undue essentialist assumption about culture (for a discussion, see Festenstein 2005: 26-30.) The implication for multilegalism (in the form discussed here) is clear: It also relies on an unfounded assumption concerning cultures; we cannot neatly divide the polity into culturally salient groups, so the idea must be abolished. The normative problems of assuming that a person belongs seamlessly to «a culture» are the familiar ones concerning autonomy, consent, etc.

The argument as it is presented here is insufficient to undermine either multiculturalism or multilegalism. Few serious people query that culture is a contestable, politicized, and porous concept, or that persons can have overlapping cultural affiliations and identities. On this score, all that is needed for multiculturalism to be intelligible is that persons gravitate sufficiently toward certain and differently culturally tinged or (co-)determined ideas and conceptions to make it comprehensible to speak about the presence of «different» cultures within the same political sphere, or state.

However, the contention points to a salient normative issue that is somewhat intertwined with the socio-ontological questions, even if the accusation of essentialism is set aside. A defensible multilegal arrangement is, ex hypothesis, the result of a dialogical construction between a majority jurisdiction and some entrepreneurs who claim to be representative of a salient cultural group with a specific claim to certain forms of legal auto- 
nomy. But who are the parties picked out as, or claiming to be, «representative?»; what do they represent, and in virtue of what? Imagine that a person has overlapping, perhaps even competing, allegiances and affiliations. He or she might feel the attractions of cultures X, Y, Z..., while simultaneously having misgivings about aspects of the very same cultures (indeed, it seems part and parcel of a liberal outlook to make room for such identities or valuations.) Say, he or she might value the official, political, and legal genderneutrality of liberal societies while valuing a more traditional, paternalistic religious code as regards aspects of private life. Now, if representatives of a more conservative interpretation of the religious code, which «spills over» into less private, more political or public aspects of life, monopolize the interpretation of that culture's «innate» ideas and express those in the legal codes of a minority jurisdiction under multilegalism, then it seems weird to say that 1) their identity or culture is somehow «more respected» and 2) that their options or opportunities in life are enhanced in a relevant sense. Naturally, such a situation might arise in any kind of legal arrangement, and is morally problematic whether or not it takes place in a «normal» or a multilegal framework. ${ }^{23}$ The point is first that multiplying the amounts of jurisdiction might mean more risk of creating or amplifying such problems (at least if the initial situation is one of a «decent» or «liberal» jurisdiction, to extend Rawls' (1999) terms, and second, that entrenching, or recognizing, or prioritizing specific cultural codes will provide impetus for a «culturalization of the political», undermining the public/private distinction.

Here, it might be claimed with initial validity that multilegalism as described rests on informed consent - that is, entry into a cultural identity and its eventual legal status under multilegalism is voluntary and not based on some «culture police» assigning cultural identities to persons - and hence, nothing forces a given person to enter a minority jurisdiction status. However, this is too hasty. Sometimes options and opinion force themselves on persons, especially in the social sphere (as J.S. Mill reminds us with considerable force in On Liberty, see Mill, XVII: 220) and sometimes, the creation of a specific option precludes other options. Imagine a person who (plausibly) identifies himself or herself as 1) an immigrant, 2) member of an underprivileged class, and 3) some ethnic background. If entrepreneurs within this person's background define a multilegal minority jurisdiction primarily in terms of religious ideals, and this is the plausible way of remedying the underprivileged status borne by the person in question, then in some sense the religious identity is forced upon him or her.

This last point is especially interesting. Identities are not just picked out from an already existing, non-negotiated or politically unmediated reality: a political decision might create an identity. ${ }^{24}$ This can become normatively problematic if the identity in question, or the cultural interpretation built upon, precludes other relevant options, ossifies a particularly illiberal identity and coerces persons toward adopting that stance, or prevents the formation of more hybrid and flexible identities, which, in many respects, is precisely what the fact of pluralism calls for. In sum, in itself, the allegation that multicultural multilegalism builds upon a theoretically incoherent or normatively unpalatable picture of cultural essentialism does not have much critical force. That being said, forcing a rigid and narrow interpretation of cultural identity upon (perhaps vulnerable) members 
of a minority is a relevant worry. Hence, if a multicultural multilegalist system should be initiated, it is important to include various voices and strata of the minority in question in the construction of that system, as well as to try to make sure that the legal powers given do not end up exclusively in the hands of some self-serving elite within the minority and that the legal powers do not give some parties in the minority group unfair and irrevocable advantages in the future construction of cultural identity.

\section{Conclusion}

It is impossible in this short space to do full justice to complicated legal and normative issues such as the ones presented here. Nevertheless, some tentative conclusions do arise: The allegation that multilegalism should in itself, or by default, be morally undesirable seems hard to demonstrate. None of the normative worries raised here constitute a «knock-down» argument to the effect that any and all forms of multilegalism are normatively repugnant. In this sense, multilegalism is a notion worth discussing and, in certain circumstances, considering as a practical suggestion. This might seem trivially true, insofar as it is true that various forms of multilegalism take place in «normal» legal systems; nevertheless, it is important to remind ourselves that this is indeed the case.

However, while not all of the normative concerns mentioned seem insurmountable or likely to arise, there are many and rather disturbing legal and normative challenges connected with the idea of multicultural multilegalism - challenges that should temper any immoderate and far-reaching claim for multicultural multilegalism:

First, the complexities surrounding the issue of choice of law are on the one hand inevitable (barring the cosmopolitical solution of a single legal system for the entire world) as we have competing national and international legal sources; on the other hand, preexisting complexity is not an excuse for multiplying complexity by creating more and possibly competing legal sub-systems.

Second, the consequences of multicultural multilegalism for social cohesion, community spirit, etc. might be detrimental, and for any concrete suggestion of a multicultural multilegal arrangement, this should be factored in when an all-things-considered assessment is to be made. Obviously, this is an empirical question relying on a great variety of dynamics and aspects, and it is wrong to claim that detrimental effects will arise in any and all circumstances, or that these effects outweigh positive contributions from a multilegal arrangement in all cases.

Third, any defensible form of multicultural multilegalism must strike a balance between the aims of cultural recognition (or equality, identity, etc.) with protection of individual rights against in-group dominance, marginalization, etc. To this end, Kymlicka's scheme of (justifiable) external protections vs. (unjustifiable) internal restrictions is probably useful, although it will seriously limit the range of defendable legal practices and codes within a minority jurisdiction.

Fourth, issues concerning recognition do not seem in themselves sufficient to play a role in an argument for multicultural multilegalism, as existing legal systems already give 
consenting parties leeway to make a wide array of agreements in civil law courts; or, many of the claims made based on recognition could be met by instigating special rights within the existing legal system.

The practical implications of these reflections can plausibly be summed up as follows: First, we cannot a priori eschew consideration of multicultural multiculturalism. The issue invites a piecemeal, case-by-case approach. Hence, Waldron's purely negative assessment is too hasty. Second, any defensible form of multicultural multilegalism must rather be circumscribed, hemmed in by a host of competing normative aims such as respect for individual rights, the fact that many cultural claims can be accommodated within preexisting frameworks of rights and laws, the wish to avoid unnecessary legal complexities such as those associated with choice-of-law types of problems, and the aim of social cohesion or solidarity across cultural boundaries.

\section{Notes}

${ }^{1}$ Throughout, «multiculturalism» without qualifications denotes the philosophical and normative agenda of multiculturalism, not the empirical claim that some state is de facto multicultural.

2 This article has benefitted much from discussions of its central ideas with the people at CESEM - The Centre for the Studies of Equality and Multiculturalism, Copenhagen University. Moreover, I am grateful for the support from the Danish Research Council, FKK.

${ }^{3}$ See, e.g., Shachar (2001: 2). The term «Nomos group» originates from Cover, R. (1983) The Supreme Court 1982 term Foreword: nomos and narrative. Harvard Law Review, 97, pp. 4-68. On the difference between legal and cultural identity, see below.

${ }^{4}$ See, e.g., Petersen \& Zahle (1995).

${ }^{5}$ See, e.g, Arnaud (1995: 149).

${ }^{6}$ The contemporary legal theoretical discussion (e.g., scholars such as Moore, Griffiths, Merry, Berman) tends to describe «legal pluralism» as a state of affairs in which there are two distinct legal orders competing for supremacy. Against this, I claim that «legal pluralism» can apply to competing yet not wholly distinct legal orders. But I admit that one might describe what I am focusing on here as a case of legal devolution or decentralization. I discuss the concept of multilegalism in much greater length in Nielsen (2011).

${ }^{7}$ See, e.g., http://www.theus.org.uk/the_united_synagogue/the_london_beth_din/about_us/ (accessed 01-09-2013).

${ }^{8}$ The issues here must not be confused with the in certain ways much more radical skein of problems that are connected with secession. Hence, questions of more or less full autonomy for national minorities/ indigenous people, regions etc., are not central for this article.

${ }^{9}$ Compare Forsyth (2007) passim.

${ }^{10}$ See Nielsen $(2011)$.

${ }^{11}$ E.g., Raz (1994; 1998); Spinner (1994); Tamir (1993).

${ }^{12}$ See, e.g., Kymlicka (1995). He also invokes the more straightforward egalitarian argument presented in the above.

${ }^{13}$ Of course, this map of multiculturalism could be drawn in a number of different yet plausible ways.

${ }^{14}$ For the following, see Shachar (2001: 2 and note 5).

${ }^{15}$ Shachar (2001: 2, note 5, refering to Greene (1996: 4), Kiryas Joel and Two Mistakes about Equality. Colombia Law Review, 96); Shachar (2001: 2).

${ }^{16}$ It must be granted that the exact demarcation line between preferences that are «cultural» and those that are «legal» is hard to draw. Hence, the difference between one's cultural and one's legal identity is 
blurry as well. However, it also seems evident that some (groups of) persons have (even quite strong) cultural preferences, say, for rules and customs that should guide family life, or consumption of food, or dress codes, but at the same time have no, or only very weak preferences to the effect that these should «spill over» into any legal arenas. In short, those preferences should not be encapsulated in law. Hence, on the assumption that we are talking about a cultural minority, one might describe their identities as culturally different (vis-à-vis the majority) but legally identical to the majority. Conversely, some (groups of) persons do hold it as an important part of their identity that these preferences should be expressed in law, at least the law that governs their own business.

${ }^{17}$ I address this legal question at some length in Nielsen (2011).

${ }^{18}$ For 2) through 4), see Waldron $(2002,2007)$ passim.

${ }^{19}$ The following is partly built on Dane (2010).

${ }^{20}$ This is not the place to go into the universalist/relativist debate, but for one clear and short defence of universalism, see Caney (2005: chapter 2).

${ }^{21}$ The line of thought invites a (huge) question that cannot be adequately addressed in this article, namely whether and which forms of political-legal guarantees against future misuse of the powers granted should be accepted by minorities upon instigating a multilegal system, not to mention which forms of sanctions are permissible in cases of non-compliance.

22 This naturally raises a host of problems concerning exit rights, see, e.g., Okin (2002).

${ }^{23}$ Indeed, what many liberals throughout the Western world fear about conservative forces in their societies is precisely that they will enforce culturally based norms in the legal system that might infringe individual liberty, regardless of any issues of multilegalism.

${ }^{24}$ See Malik (2009).

\section{References}

Arnaud, A-J. (1995) Legal Pluralism and the Building of Europe. In Legal Polycentricity - Consequences of Pluralism in Law, eds. H. Petersen \& H. Zahle, pp. 149-169. Dartmouth: Aldershot.

Banting, K. \& Kymlicka, W. (eds.) (2006) Multiculturalism and the Welfare State. Oxford: Oxford University Press.

Caney, S. (2005) Justice beyond Borders. Oxford: Oxford University Press.

Dane, P. (2010) Conflict of Laws. In Blackwell Companion to Philosophy of Law and Legal Theory, ed. D. Patterson, pp. 197-208. Chichester: Blackwell.

Festenstein, M. (2005) Negotiating Diversity. Cambridge: Polity Press.

Forsyth, M. (2007) A Typology of Relationships Between State and Non-state Justice Systems. Journal of Legal Pluralism and Unofficial Law, 56, pp. 67-112

Fraser, N. \& Honneth, A. (2003) Redistribution or Recognition? London: Verso.

Honneth, A. (1995) The Struggle for Recognition: The Moral Grammar of Social Conflicts. Cambridge: Polity Press.

Ikäheimo, H. (2002) Taylor on Something Called «Recognition». In Perspectives on the Philosophy of Charles Taylor, ed. A. Laitinen \& N. H. Smith, pp. 99-111. Acta Philosophica Fennica 71. Helsinki: Societas Philosophica Fennica.

Johnson, J. (2002) Liberalism and the Politics of Cultural Authenticity. Politics, Philosophy and Economics, 1, pp. 213-236.

Kymlicka, W. (1995) Multicultural Citizenship. Oxford: Oxford University Press.

Kymlicka, W. (2001) Politics in the Vernacular: Nationalism, Multiculturalism, and Citizenship. New York: Oxford University Press.

Kymlicka, W. (2002) Contemporary Political Philosophy (2. Ed.). Oxford: Oxford University Press. Malik, K. (2009) From Fatwa To Jihad: The Rushdie Affair And Its Legacy. London: Atlantic Books. 
Mill, J.S. (1963-1991) Collected Works. Edited by J.M. Robson. London: Routledge.

Modood, T. (2007) Multiculturalism: A Civic Idea. Cambridge: Cambridge University Press.

Nielsen, M.E.J. (2011) Multicultural Multilegalism - Definition and Challenges. Les Ateliers de l'Éthique, 6 (2), pp. 126-154.

Okin, S.M. (2002) Mistresses of Their Own Destiny: Group Rights, Gender, and Realistic Rights of Exit. Ethics, 112 (2), pp. 205-230.

Parekh, B. (2006) Rethinking Multiculturalism: Cultural Diversity and Political Theory. Basingstoke: Palgrave Macmillan.

Petersen, H. \& Zahle, H. (eds.) (1995) Legal Polycentricity - Consequences of Pluralism in Law. Dartmouth: Aldershot.

Phillips, A. (2003) When Culture Means Gender: Issues of Cultural Defence in the English Courts. The Modern Law Review, 66 (4), pp. 510-531.

Rawls, J. (1999) The Law of Peoples with 'The Idea of Public Reason Revisited'. Cambridge, Mass.: Harvard University Press.

Raz, J. (1994) Multiculturalism: A Liberal Perspective. Dissent (winter), pp. 67-97.

Raz, J. (1998) Multiculturalism. Ratio Juris, 11(3), pp. 193-205.

Shachar, A. (2001) Multicultural Jurisdictions: Cultural Differences and Women's Rights Cambridge: Cambridge University Press.

Spinner, J. (1994) The Boundaries of Citizenship: Race, Ethnicity and Nationality in the Liberal State. Baltimore: John Hopkins University Press.

Tamir, Y. (1993) Liberal Nationalism. Princeton; Princeton University Press.

Taylor, C. (1994) The Politics of Recognition. In Multiculturalism (2. Ed.), ed. A. Gutmann, pp. 2574. Princeton: Princeton University Press.

Waldron, J. (2002) One Law for All: The Logic of Cultural Accommodation. Washington and Lee Law Review, 59 (3), pp. 3-34.

Waldron, J. (2007) Status versus Equality: the Accommodation of Difference. In Multiculturalism and Law: A Critical Debate, ed. O. A. P. Shabani, pp. 129-155. Cardiff: University of Wales Press.

Young, I.M. (1990) Justice and the Politics of Difference. Princeton: Princeton University Press. 